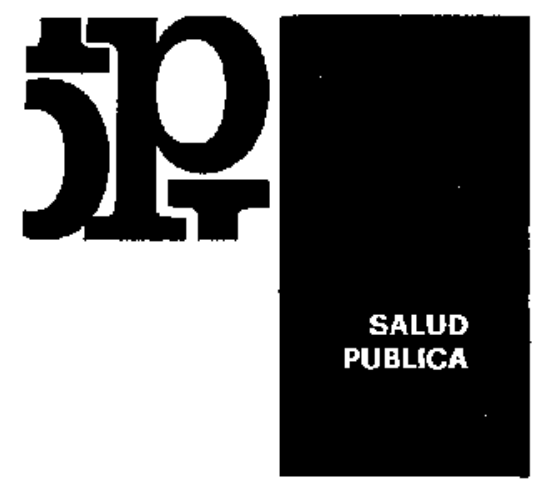

\title{
Enfermedades del aparato respiratorio vistas por el Inmunólogo
}

\author{
DR. RICARDO SORENSEN * y DRA, LILIANA REBOLLEDO *",
}

La inmunología moderna estudia las reacciones tisulares que suceden en un organismo cuando éste se pone en contacto con una substancia o céhula extraña. Una región del organismo tan activamente expuesta al medio ambiente como es el aparato respiratorio necesariamente es un sitio en el cual estas reacciones tisulares adquieren una gran importancia, tanto como mecanismo normal de defensa, como constituyendo el órgano de choque para los efectos nocivos que conocemos como hipersensibilidad. Para el inmunólogo, y aún a riesgo de simplificar en exceso el problema, es tentador clasificar gran parte de la patología del árbol respiratorio en aquella causada por infecciones, que sólo son posibles cuando los mecanismos de defensa son sobrepasados, y en otro gran grupo en el cual la reacción del organismo contra un agente, que puede no ser causante de patología en sí, es tan exagerada, o tan deficientemente inhibida, que causa daño.

Si bien los avances en nuestro conocimiento de la inmunología son impresionantes debe reconocerse que en la actualidad, probablemente, ha introducido muchos más problemas de los que ha aclarado. Sería imposible pretender agotar este terna, por lo cual pensamos que es preferible presentar un esquema, un modelo de cómo vemos actualmente el problema y que permita a cada uno de los lectores aceptarlo, corregirlo o destruirlo según lo vayan imponiendo los hechos concretos que se observen en la clínica y en la experimentación.

En nuestro esquema se ha reunido la probable secuencia de una reacción humoral frente a un agente agresor; como mecanismo de defensa esta

\footnotetext{
- Unidad de Inmunologia. Depto. Pediatría, Area Oriente. De. partámento de Inmunopatologla, Instituto Bacteriológica.

** Q. F. Laboratorio de Investigación, Depto. Pediatra, Arca Oriente, Hospital L. Calvo Mackenua.
}

reacción es efectiva en infecciones virales y frente a muchas agresiones bacterianas. Las reacciones de hipersensibilidad pueden ser causados además por una serie de substancias inertes que a menudo son inhaladas (alérgenos). Pero no debemos olvidar que el sistema de inmunidad adaptativa no reacciona frente a ила substancia extraña llegando finalmente sólo a la síntesis de anticuerpos (defensa moral) sino también poniendo en juego un importante mecanismo de defensa celular específica a cargo de linfocitos sensibilizados. Estos actúan directamente o por medio de una serie de mediadores, que no son anticuerpos, en contra de Ia substancia que ha desencadenado su reacción específica. Este mecanismo de defensa es especialmente importante frente al bacilo de Koch y frente a hongos. Igual que el humoral se expresa tanto a nivel local, en las mucosas, como en el sistema Iinfático y torrente circulatorio con sus respectivas zonas de reconocimiento, ganglios linfáticos y bazo.

Para completar esta visión panorámica de Jos mecanismos de defensa a nivel del árbol respiratorio, debemos decir que también aquí los mecanismos inespecíficos, integridad de barreras anatómicas, fagocitosis, complemento, interferón, etc. juegan un importante papel. Su relación con los mecanismos específicos que lifevan a la síntesis de anticuerpos y/o a la aparición de linfocitos sensibilizados son múltiples y pueden localizarse en 2 partes de la respuesta inmune: en la fase de captación del antígeno (iniciación de la respuesta) y luego como amplificadores de los efectos de una respuesta específica, magnificando las consecuencias biológicas de ésta. Como ejemplo podemos citar una reacción como la siguiente: fagocitosis de un bacterio con procesamiento de material antigévico y traspaso de información al sis- 
tema inmunocompetente $\rightarrow$ reacción específica: síntesis de inmunoglobulinas y reacción de ésta con su antígeno $\rightarrow$ amplificación inespecífica: atracción de complemento at sitio de reacción; éste atrae a leucocitos y finalmente éstos liberan enzimas lisosómicos (que constituyen un arma muy potente de destrucción). Una reacción similar, cambiando al complemento y los leucocitos por. la atracción directa de macrófagos por parte de Ios linfocitos sensibilizados puede anotarse para las reacciones do inmunidad celular.

Para un antígeno que ingresa desde el exterior por la vía respiratoria la secuencia de las respuestas que va a encontrar está resumido en la tabla No 1. Vale la pena destacar algunos hechos de importancia para cada una de las etapas que se han diferenciado.

1.- La principal inmunoglobulina que entra a las secreciones es la IgA. Esta ingresa en forma de un dímero, en que 2 inmunoglobulinas van unidas por una tercera estructura sintetizada por los epitelios de las mucosas, y que se llama pieza secretoria. Esta da estabilidad a la molécula de IgA en las secrecioncs. Se ha demostrado que la IgA es efectiva en la neutralización de algunos virus y probablemente también en la eliminación de substancias inertes; no se conoce su efectividad como mecanismo de defensa frente a bacterias. Esta puede ponerse en duda, pues la IgA no capta complemento y tampoco se conocen polimorfonucleares o macrófagos que tengan receptores para ella, que le permitan unirse a estas células y luego ser fagocitada junto al antígeno al cual se encuentra fijada. Otra característica interesante es que la respuesta de cste sistema es muy localizada al área de la mucosa que se ba puesto en contacto con el antígeno. La deficiencia de IgA tanto en suero como en secreciones es la deficiencia que con más frecuencia sc observa en el ser humano y será discutida más en detalle en otros artículos en esta misma revista. Baste decir aqui que la deficiencia aislada de IgA puede ser un hallazgo casual en personas sanas, pero que por otra parte se le encuentrá en relación con hipersensibilidad y con infecciones a repetición. En el primer caso seguramente falla la barrera que para muchos virus y substancias extrañas constituye la IgA en secreciones; ef segundo caso se observa, en general, cuando la defjciencia de IgA se va asociando a otras alteraciones de la respuesta inmune (por ej. deficiencia IgE).

2 a.- La inmunoglobulina $\mathrm{E}$ tiene en su estructura características que la hacen unirse a las membranas de células cebadas y basófilos, de tal suerte que sus sitios activos queden libres y expuestos hacia el exterior permitiendo su interacción con antígenos.

Cuando se dan las condiciones (tamaño o configuración del antígeno, alérgeno, y densidad de IgE en la membrana celular) para que se forme un puente que una a 2 moléculas de IgE, se desencadenan dentro de la célula una serie de reacciones bioquímicas que se resumen en la tabla No 2 y que conducen a la liberación de substancias vasoactivas, mediadores. Esto constituye una reacción normal de inflamación contribuyente a hacer más efectivo un mecanismo de defensa; pero que en algunas personas causa patología por ser excesivamente intensa (hipersensibilidad tipo I o inmediata) o por no estar adecuadamente regulada por inhibjdores fisiológicos (individuos atópicos).

Si observamos la tabla No 2 vemos que después de la interacción específica entre antígenono e IgE fija a la célula se produce la activación del sistema enzimático intraceJular, conduciendo a la liberación de mediadores. La activación de la adenilciclasa, enzimo fijo a la membrana celular, permite la síntesis de AMP 3'-5' cíclico a partir de ATP adcrosin trifosfato, y de ribosa fosfato en presencia de iones $\mathrm{Mg}$. Por otra parte la fosfodiesteraque es una nucleotidasa, degrada el AMP 3'-5' cíclico a AMP-5' (ácido adenilico) tambíén en presencia de iones Mg. Basándose en esta secuencia se han efectuado experiencias tendientes a mostrar la modulación de la liberación de mediadores, con sustancias que aumentan o disminuyen los niveles intraceiulares del AMP 3'-5' cíclico. Así, las sustancjas que aumentan estos niveles, inhiben la liberación de mediadores como Ia histamina o la sustancia de reacción lenta de Ia anafilaxia (SRL-A). Por el contrario, la disminución de la concentración de AMP 3'-'5 cíclico produce aumento en la liberación de mediadores.

Las sustancias que ejercen esta acción son en su mayoría catecolaminas y se han expuesto en la tabla 2 de acuerdo con su acción.

El sistema bronquial es influenciado por las catecolaminas. Aquéllas que afectan los alfa receptores producen bronco-contricción, y aquéllas que afectan los beta recetores producen relajación bronquial, de modo que, hay un balance entre ellas. La adenilciclasa es un beta receptor, de modo que, su activación cataliza la síntesis del sistema enzimatico intracelular. El efecto contrario se obticne con las sustancias alfa adrenérgicas. En la tabla No 2 se han anotado asimismo, las sustancias antagónicas correspondientes y los efectos obtenidos. Es importante observar el efecto sinérgico que se obtiene con isoproterenal y aminofilina en el efecto inhibitorio de los mediadores. Esto podría deberse a que la aminofilina actúa a nivel de la fosfodiesterasa produciendo un bloqueo de ésta lo que contribuye también al aumento del AMP 3'-'5 cíclico.

Se ba postulado que los pacientes asriáticos han heredado o adquirido una deficiencia del enzimo 
adenilciclasa, lo que resulta en una actividad desproporcionada de los alfareceptores.

2 b.- Un 50\% de la IgG se encuentra en el espacio extravascular. Es el efector de inmunidad humoral específica por excelencia $y$ su ausencia causa infecciones a repetición, al igual que IgM; 3 de las 4 subclases de IgG son capaces de captar complemento y a través de esta propiedad adquieren un gran significado biológico, tanto como mecanismo de defensa, como por ser causante de lesiones tisulares en determinadas condiciones (hipersensibilidad tipo III o enfermedad por complejos inmunes). Puesto que la formación de complejos antígeno-anticuerpo es la finalidad de la respuesta inmune, la pregunta que salta a la vista es en qué condiciones esta formación de complejos pasa a inducir daños. Hay por lo menos 2 factores bien conocidos: En primer lugar el tamaño molecular del complejo inmune, que debe ser grande (mayor que 195). El tamaño a su vez depende de la proporción entre antígeno y anticuerpo, encontrándose la formación de complejos mayores en la zona de equivalencia o cerca de ella. En segundo lugar se ha demostrado que el depósito de complejos inmunes se favorece grandemente por la apertura del árbol vascular, inducido por las substancias vasoactivas que median las reacciones de hipersensibilidad tipo I (inmediata). Este hecho se ha estudiado a nivel del glomérulo e igualmente ha sido demostrado por Peppys a nivel pulmonar usando antígenos de hongos. Al inhalar estos antígenos algunos pacientes presentan una crisis aguda de asma causadas por el mecanismo de hipersensibilidad inmediata. Se produce una récuperación espontánea, pero a las $6 \mathrm{u}$ 8 horas vuelve a producirse una crisis asmática sin mediar una nueva inhalación de antígeno. Esta se debe a la formación de complejos antígeno-anticuerpo. Lo interesante es que bloqueando la primera fase con Cromoglicato sódico (que no es efectivo para bloquear la 2 a crisis) no se produce la crisis tardía.

Aquí es conveniente describir brevemente un mecanismo de daño que obedece a una causa enteramente distinta, si bien relacionada con las anteriores. La acción de las enzimas de los lisosomas de los macrófagos alveolares que actúan, ya sea, directamente $o$ atraídos por anticuerpos como opsoninas, es frenada normalmente por un complejo sistema de inhibidores, la alfa 1 antitripsina. Esta constituye el $80 \%$ de las alfa 1 globulinas que se detectan en la electroforesis sobre papel. En individuos en que la alfa 1 antitripsina está muy disminuida debido a una alteración genética, sucesivas infecciones, a las cuales no son más susceptibles que lo normal, van causando un daño tisular que lleva a la formación casi invariable de enfisema.
3.- Si seguimos la vía de un virus o bacterio que ingrese por vía respiratoria, y que logre romper todas las barreras descritas, éste puede pasar al torrente circulatorio. La importancia de los anticuerpos y/o linfocitos circulantes debe considerarse en conjunto con los sitios de reproducción. y acción patológica del agente. $\mathrm{El}$ virus polio por ejemplo, a nivel de la mucosa causa lesiones de escasa importancia y viene a ejercer el daño que le caracteriza sólo después de localizarse en SNC adonde llega por vía sanguínea. Esto explica que tanto una vacuna que estimulan la defensa local, (vacuna Sabín) como una que prácticamente no induce anticuerpos secretados, sino sólo circulantes, (vacuna Salk) sean igualmente efectivas. En el caso de la vacuna BCG, que se aplica por vía parenteral $y$, por lo tanto, estimula fundamentalmente la aparición de linfocitos sensibilizados en circulación, la mayor diferencia entre vacunados y no vacunados no se encuentra en la incidencia de tuberculosis pulmonar, sino de su complicación meníngea. Por otra parte, para aquellos virus (influenza, etc.) que tienen especial tropismo por el árbol respiratorio, la tendencia actual es encontrar vacunas que estimulen preferentemente los mecanismos de defensa locales.

La observación de la tabla Nọ 1 nos permite también delinear las características especiales de las reacciones inmunes en el árbol respiratorio del lactante. Tanto el sistema de IgA secretado como el desarrollo de IgE son más lentos durante la evolución, lo que permite una mayor acción de la IgM e IgG a nivel de las mucosas. La bronquiolitis puede interpretarse como una reacción de hipersensibilidad tipo III. El desencadenante puede ser por ejemplo el virus respiratorio sincicial. En una experiencia muy interesante se observó que la vacuna parenteral (anticuerpos IgG-IgM) aumentaba en vez de disminuir la bronquiolitis, mientras que vacunas locales (IgA secretada) sí disminuyeron efectivamente estas crisis.

En la tabla No $^{0}$ se han numerado los distintos test y técnicas de Laboratorio que permiten estudiar diversos aspectos de los mecanismos de defensa a nivel del árbol respiratorio y de la patología atribuible a sus observaciones.

El conjunto de test podemos agruparlos en 2 grupos: aquéllos destinados a conocer la integridad de los mecanismos de defensa, y aquéllos que detectan mecanismos de hipersensibilidad.

En el primer grupo podemos anotar, siguiendo siempre el orden cronológico de la respuesta, la determinación de los niveles de IgA en secreciones, la detección de la presencia de IgE unida a los tejidos por medio de las reacciones con suero anti-IgE, y la determinación de los niveles circulantes de inmunoglobulinas. No debe descuidarse la observación del No absoluto de linfocitos circulantes en el hemograma, como un índice de in- 
munidad celular. En el mismo sentido podemos valorar la presencia de anticuerpos específicos. Aun una reacción cutánea inmediata frente a un alérgeno es un índice indirecto de la presencia de IgE en ese paciente. La medición de isoaglutininas, técnica muy simple de realizar, documenta la presencia de anticuerpos circulantes. Una reacción de tuberculina positiva, ya sea en un vacunado o en un infectado, desde el punto de vista inmunológico documenta la capacidad de montar una respuesta inmune celular.

Las evidencias de mecanismos de hipersensibilidad las debemos buscar antes que nada en los resultados de técnicas relativamente simples, como son los test cutáneos. Lo importante en ellos es no dejar de observar reacciones tardías (6-8 hrs.), atribuibles a formación de complejos inmunes, y que probablemente seleccionan a un grupo especial de pacientes en que el tratamiento de hiposensibilización puede resultar contraproducente. Para este grupo es importante considerar la medición seriada de niveles de complemento, por cuanto un consumo de él certifica este mecanismo de hipersensibilidad.

La presencia de precipitinas anti-hongo aysda a encontrar un agente causante $y$, si se presentan reacciones a las 6-8 hrs., también un posible mecanismo de acción patológica. Para este grupo de agentes, en los cuales como mecanismo de defensa la máxima efectividad está en la inmunidad celular, tienen especial importancia las reacciones tardías (48-72 hrs.) que son propias de este tipo de inmunidad.

Desde que se ha identificado claramente a la IgE como causante de reacciones de hipersensibilidad, se ha despertado un gran interés en la medición, tanto de sus niveles globales, como de anticuerpos específicos contenidos en esta fracción de inmunoglobulinas. Si bien la determinación de IgE tiene indudable interés pará la comprensión de la hipersensibilidad tipo I, las dificultades técnicas y la escasa información útil que presta al clínico hacen que su introducción en laboratorios de rutina no sea indispensable.

Con los examenes relativamente simples que hemos enumerado $\mathrm{y}$ la adecuada interpretación de sus resultados, se da un efectivo paso hacia el mejor estudio de pacientes con enfermedades broncopulmonares. Por una parte, evitamos el riesgo de no reconocer oportunamente una inmunodeficiencia de cualquier tipo que condicione la patología observada, $y$, por otra parte, se puede reconocer el probable mecanismo de hipersensibilidad involucrado.

Los aspectos terapéuticos de mayor importancia se enumeran en las tablas No 1 y No 2. Sería imposible analizarlos en detalle acá, por lo cual discutiremos sólo dos aspectos.

Está demostrado que la hipersensibilidad tipo
III, que causa un daño mucho más profundo, debe ser precedido por una reacción de hipersensibilidad tipo I, que podemos combatir en forma más efectiva. Esta inhibición puede realizarse a nivel de la IgE misma (cromoglicato sódico) o combatiendo los efectos de los mediadores liberados con antihistamínicos, adrenalina, etc. Al enfrentar, por ejemplo, una crisis asmática severa y prolongada, con frecuencia las medidas tendientes a combatir la hipersensibilidad inmediata no tienen mayor efecto, y debemos recurrir a corticoides que son más efectivos para combatir los efcctos de hipersensibilidad tipo III. En pacientes en que ésta secuencia se repite a menudo, podría tener efccto el uso decidido y precoz de antihistamínicos ante los menores signos de desencadenamiento de una nueva crisis.

La práctica tan usada de realizar tratamientos de biposensibilización, y cuyos resultados positivos en muchos casos son evidentes, debe también discutirse, aun cuando sea muy brevemente. Para ello conviene separar los pacientes según su edad. Dada la situación especial descrita para el nirio menor, muchos de los éxitos de tratamientos de hiposensibilización en este grupo pueden atribuirse a un desarrollo normal del sistema inmunológico, con aparición de barreras más efectivas para su defensa. En el niño mayor y en el adulto el problema es distinto. Si se trata comprobadamente de hipersensibilidad tipo I, debemos postular que o falla alguna barrera de defensa, o están exagerados o deficientemente inhibidos los mecanismos de hipersensibilidad inmediata.

Entonces, ¿cuál es el papel de la hiposensibilización, en que un antígeno es administrado parenteralmente y estimula en primer término la aparición de anticuerpos circulantes? Se sabe que en la medida que se prolonga una estimulación antigénica, con bajas dosis de antígeno, se van seleccionando clones de linfocitos de cada vez mayor afinidad por el antígeno. El producto de la estimulacion de estos clones es un anticuerpo de afinidad también cada vez mayor. Los clones que dan origen a anticuerpos de afinidad menor dejan de ser estimulados, pues ya no captan el antígeno indispensable para ser reestilados. Este reacciona con los anticuerpos de mayor afinidad, que pueden ser los responsables de uno de los efectos de la hiposensibilización, compitiendo ventajosamente con la IgE por la captación del antígeno (alérgeno). Si se analiza nuevamente la secuencia anotada en la tabla $N^{0} 1$, veremos que la hiposensibilización más lógica a nivel del árbol respiratorio debería inducir más bien la estimulación de anticuerpos secretados (IgA 11 S.).

Poco sabemos actualmente sobre el efecto de los procedimientos clásicos de hiposensibilización sobre la inducción de esta barrera defensiva. La duda que salta a la vista es cuál es el defecto de 
la respuesta inmune en los pacientes asmáticos (asma extrínseca), puesto que reciben una estimulación antigénica cada vez que se enfrentan con el alérgeno. Para inducir una respuesta de IgA secretoria con finalidad terapéutica debemos conocer muy bien primero el o los alérgenos causantes, y luego aprender a administrarlos de tal manera que induzcan una respuesta inmune sin causa: problemas iguales o mayores que los que estamos tratando, desencadenando crisis asmáticas cada vez que se efectúa un ensayo de hiposensibilización local.
Hemos anotado en la tabla No 1 algunos de los problemas más interesantes que deberán conocerse más a fondo en los próximos años, y al hablar de hiposensibilización ya habíamos Ilegado a la problemática central de las reacciones de hipersensibilidad. Deberá conocerse mucho más de Ia naturaleza de los alérgenos, de su forma de estincular y de regular la reacción inmune, para que se logre la manipulación de ella de manera de obtener resultados positivos para los pacientes directa o indirectamente afectados por alteraciones inmunológicas.

TABLA No 1

MODELO DE LA RESPUESTA INMUNE HUMORAL EN EL ARBOL RESPIRATORIO Y SU RELACION CON HIPERSENSIBILIDAD

\begin{tabular}{|c|c|c|c|c|}
\hline Atergerto & $\begin{array}{c}1 \\
\text { Secteclones }\end{array}$ & $\begin{array}{c}2 \mathbf{a} \\
\text { Mucosa }\end{array}$ & $2 b$ & $\stackrel{3}{\text { Sangre }}$ \\
\hline$\Delta \Delta_{\Delta}^{\Delta} \Delta$ & $\underset{\rightarrow \text { Eliminación }}{\operatorname{IgA~} 11 \mathrm{~s}}$ & $\mid \underset{\mid \longrightarrow}{\longrightarrow \longrightarrow}$ Eliper tipo I. I. & $\stackrel{\text { IgG - IgM }}{\underset{\longrightarrow \rightarrow \text { Hiper tipo III Iocal. }}{\longrightarrow} \text { Eliminacion. }}$ & $\begin{array}{l}\text { I8G - IgM } \\
\text { Infección điseminada } \\
\text { Hiper Tipo IJI Sistérntea. } \\
\text { Eliminación. }\end{array}$ \\
\hline Exdmenes & $\begin{array}{l}\text { Determinacion: } \\
\text { IgA 11 } \mathrm{s} \\
\text { Anticuerpos especificos }\end{array}$ & $\begin{array}{l}\text { Determinacion IgE circu- } \\
\text { lante. } \\
\text { Determinacion IgE cutánea } \\
\text { Reacciones inmediatas } \\
\text { a) Test inhalatorio } \\
\text { b) Reacciones cutáneas. } \\
\text { Reacción Prausnitz- } \\
\text { Kustner. } \\
\text { Determinación IgE es- } \\
\text { pecifica. }\end{array}$ & $\begin{array}{l}\text { Precipitinas anti-hongo } \\
\text { Reacciones tardias } 6-8 \mathrm{hrs} \text {. } \\
\text { a) Test idhalatorio } \\
\text { b) Reacciones cutáneas. } \\
\text { Depósito de Igs. } \\
\text { Constumo de comple- } \\
\text { mento. } \\
\text { Determinacion Igs e in* } \\
\text { munidad celular. }\end{array}$ & $\begin{array}{l}\text { Determinacion Igs e Inmu- } \\
\text { gidad celviar. }\end{array}$ \\
\hline $\begin{array}{l}\text { Tratamiento } \\
\text { Eliminación del } \\
\text { Antígeno. }\end{array}$ & $\begin{array}{c}\text { Estimulacion respuesta } \\
\text { inmune JgA } 11 \mathrm{~s}\end{array}$ & $\begin{array}{l}\text { Bloqueo Interacción. } \\
\text { Alergeno-IgE-cromoglicato. } \\
\text { Competencia con Ac. más } \\
\text { ávidos IgG e IgM. } \\
\text { Bloqueo efectores biper- } \\
\text { sensibilidad tipo I. }\end{array}$ & $\begin{array}{l}\text { Bloqueo efectores hipersen- } \\
\text { sibilidad tipo III. }\end{array}$ & Desensibilización \\
\hline $\begin{array}{l}\text { Problemas } \\
\text { Caracieristicas de Aler- } \\
\text { renos. Condiciones de } \\
\text { inducción de respues- } \\
\text { ta inmume. }\end{array}$ & $\begin{array}{l}\text { Alteración de respues- } \\
\text { IgA } 11 \text { S (Iocal) en } \\
\text { alérgicos? (asma) }\end{array}$ & $\begin{array}{l}\text { Predisposición a sintesis } \\
\text { IgE? } \\
\text { Mayor fijacion IgE a teji- } \\
\text { cos. } \\
\text { Alteración inhibicion fisio- } \\
\text { logica de hipersensibilidad } \\
\text { tipo J. }\end{array}$ & $\begin{array}{l}\text { Condiciones para el depó } \\
\text { sito de conjugados que } \\
\text { causen daño. }\end{array}$ & \begin{tabular}{|l} 
Efectos de la \\
Desensibilización
\end{tabular} \\
\hline
\end{tabular}


TABLA No 2

REACCION DE HIPERSENSIBILIDAD TIPO I

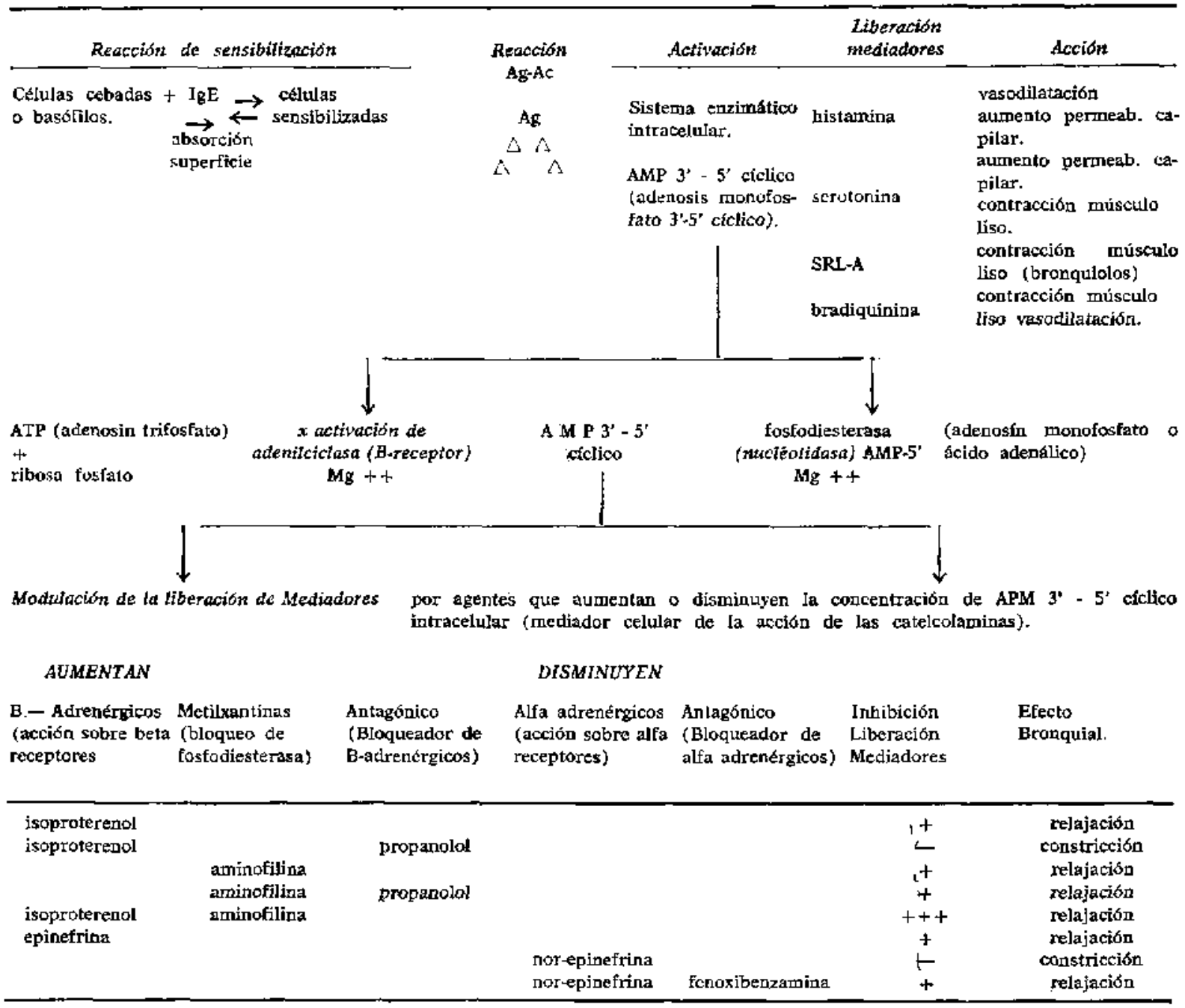

Otros agentes que inhiben la liberación de mediadores a la vez que producen desensibilización son: Dietilcarbamazida y Disodio cromoglicato. 